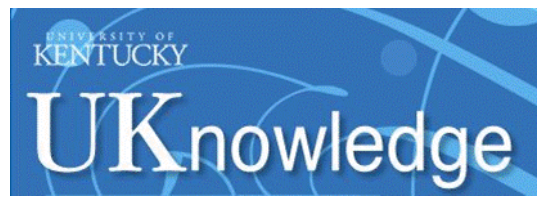

University of Kentucky

UKnowledge

\title{
Treated Hypothyroidism Is Associated with Cerebrovascular Disease but Not Alzheimer's Disease Pathology in Older Adults
}

\author{
Willa D. Brenowitz \\ University of California - San Francisco \\ Fang Han \\ Beijing University of Chinese Medicine, China \\ Walter A. Kukull \\ University of Washington \\ Peter T. Nelson \\ University of Kentucky, pnels2@uky.edu
}

Follow this and additional works at: https://uknowledge.uky.edu/pathology_facpub

Part of the Diseases Commons, Neuroscience and Neurobiology Commons, and the Pathology Commons

Right click to open a feedback form in a new tab to let us know how this document benefits you.

\section{Repository Citation}

Brenowitz, Willa D.; Han, Fang; Kukull, Walter A.; and Nelson, Peter T., "Treated Hypothyroidism Is Associated with Cerebrovascular Disease but Not Alzheimer's Disease Pathology in Older Adults" (2018). Pathology and Laboratory Medicine Faculty Publications. 34.

https://uknowledge.uky.edu/pathology_facpub/34

This Article is brought to you for free and open access by the Pathology and Laboratory Medicine at UKnowledge. It has been accepted for inclusion in Pathology and Laboratory Medicine Faculty Publications by an authorized administrator of UKnowledge. For more information, please contact UKnowledge@lsv.uky.edu. 


\title{
Treated Hypothyroidism Is Associated with Cerebrovascular Disease but Not Alzheimer's Disease Pathology in Older Adults
}

\author{
Digital Object Identifier (DOI) \\ https://doi.org/10.1016/j.neurobiolaging.2017.10.004 \\ Notes/Citation Information \\ Published in Neurobiology of Aging, v. 62, p. 64-71. \\ (C) 2017 Elsevier Inc. All rights reserved.
}

This manuscript version is made available under the CC-BY-NC-ND 4.0 license https://creativecommons.org/licenses/by-nc-nd/4.0/.

The document available for download is the author's post-peer-review final draft of the article. 


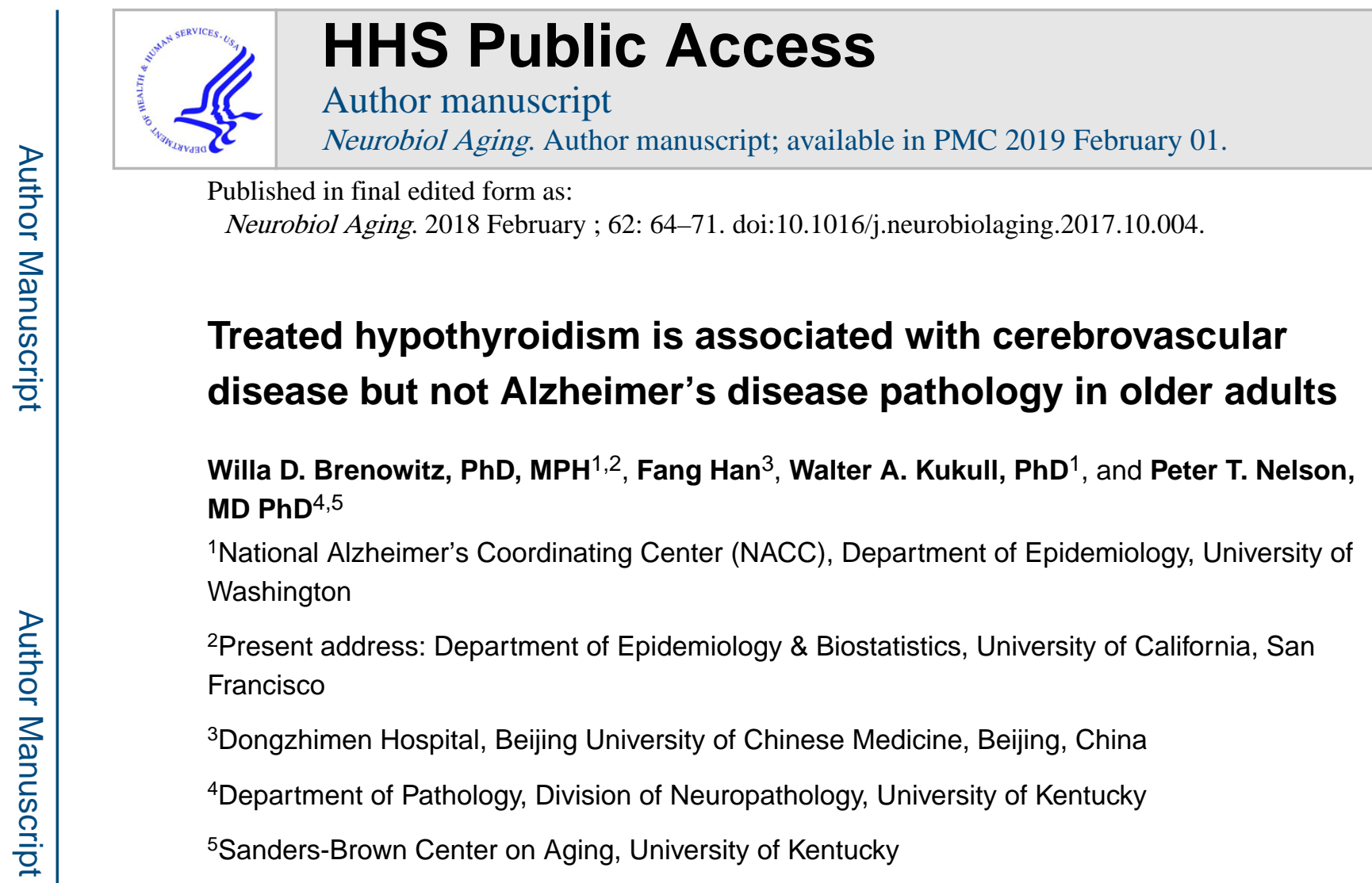

\begin{abstract}
Thyroid hormone (TH) disease is common among older adults and is associated with cognitive impairment. However, pathologic correlates are not well understood. We studied pathologic and clinical factors associated with hypothyroidism, the most common form of TH disease, in research subjects seen annually for clinical evaluations at U.S. Alzheimer's Disease Centers. Thyroid disease and treatment status were assessed during clinician interviews. Among autopsied subjects, there were 555 participants with treated hypothyroidism and 2,146 with no known thyroid disease; hypothyroidism was associated with severe atherosclerosis ( $\mathrm{OR}=1.35$ 95\% CI: 1.02, 1.79) but not Alzheimer's disease (AD) pathologies (amyloid plaques or neurofibrillary tangles). Among participants that did not come to autopsy (4,598 with treated hypothyroidism and 20,045 without known TH disease), hypercholesterolemia and cerebrovascular disease (stroke and transient ischemic attack) were associated with hypothyroidism, complementing findings in the smaller autopsy sample. This is the first large-scale evaluation of neuropathologic concomitants of hypothyroidism in aged individuals. Clinical hypothyroidism was prevalent ( $25 \%$ of individuals studied) and was associated with cerebrovascular disease but not AD-type neuropathology.
\end{abstract}

Co-Corresponding authors: Peter T. Nelson, MD PhD, 311 Sanders-Brown Center on Aging Building, 800 South Limestone, Lexington, KY 40536-0230, Tel \#: (859) 218-3862, Peter.nelson@uky.edu; Willa D. Brenowitz, PhD, MPH, Mission Hall, $55016^{\text {th }}$ St, $2^{\text {nd }}$ Floor, San Francisco, CA, 94158-2549, Tel \#: (415) 476-2300, willa.brenowitz@ucsf.edu.

Publisher's Disclaimer: This is a PDF file of an unedited manuscript that has been accepted for publication. As a service to our customers we are providing this early version of the manuscript. The manuscript will undergo copyediting, typesetting, and review of the resulting proof before it is published in its final citable form. Please note that during the production process errors may be discovered which could affect the content, and all legal disclaimers that apply to the journal pertain.

Statistical analyses: Conducted by Dr. Willa Brenowitz

All authors disclose no Conflict of Interest including any financial, personal or other relationships with other people or organizations within three years of beginning the work submitted that could inappropriately influence (bias) their work. 


\section{Keywords}

Endocrine; cerebrovascular disease; CARTS; DLB; thyroxine

\section{Introduction}

The pathologic sequelae of thyroid hormone $(\mathrm{TH})$ dysregulation in the aged human brain are incompletely understood. Among the elderly, hypothyroidism is reported in up to $30 \%$ of research participants and hyperthyroidism in up to 10\% (see (Canaris et al., 2000; Empson et al., 2007; Sawin et al., 1985; Vanderpump, 2011; Verburg et al., 2017)), and both clinical hypothyroidism and hyperthyroidism are associated with substantial morbidity and mortality (Gencer et al., 2013; Grossman et al., 2016; Imaizumi et al., 2004; Tan et al., 2008; Yeap et al., 2013).

TH is an evolutionarily ancient hormone with strong impact on human cellular metabolism, brain development, and cardiovascular health (Boelaert and Franklyn, 2005; Maenhaut et al., 2000). TH dysregulation in advanced age is also associated with risk for dementia (Chaker et al., 2016c; Mafrica and Fodale, 2008; Sampaolo et al., 2005; Tan and Vasan, 2009); a PubMed search using terms "(thyroid or thyroxine) and (Alzheimer's or dementia)" returns $>500$ published papers. The literature indicates a complicated relationship between TH and dementia risk. Hyperthyroidism is usually more strongly associated with cognitive decline, although some reports indicate that hypothyroidism also is a risk factor for dementia (Akintola et al., 2015; Chaker et al., 2016c; Moon, 2016; Moon et al., 2014; Pasqualetti et al., 2015; Rieben et al., 2016; Tan and Vasan, 2009; van Osch et al., 2004; Wu et al., 2016; Yeap et al., 2012). These are important questions, particularly since the elderly population is expanding and pharmacological manipulation of TH levels provide a possible diseasemodifying strategy.

Perhaps due to the many relevant covariates that constitute formidable potential experimental confounders, there currently is no consensus as to the mechanism(s) underlying the link(s) between TH disease and dementia. In terms of specific disease processes, lack of TH in utero and in early life causes severe cognitive impairment (a component of "cretinism"), with extensive white matter pathology (Rosman, 1972). Some studies suggest that hypothyroidism may induce structural changes in the hippocampus (Cooke GE, 2014; Koromilas C, 2010). However, much is still unknown about how TH dysregulation is correlated with brain pathologies in old age. TH dysregulation has been implicated in or comorbid with cardiovascular disease, stroke, hippocampal sclerosis of aging/cerebral age-related TDP-43 with sclerosis (CARTS), autoimmune disease(s), and, possibly, Alzheimer's disease (AD) (Chaker et al., 2017; Chaker et al., 2016b; Collet et al., 2012; de Jong et al., 2009; Frohlich and Wahl, 2017; Mafrica and Fodale, 2008; Nelson et al., 2016a; Squizzato et al., 2005; Tan and Vasan, 2009; Zhang et al., 2017). Prospective studies are few in number and lack pathologic endpoints, so cohorts that follow patients to autopsy are required to provide needed insights into how TH disease affects the aged brain.

The objective of this study was to evaluate associations between common cerebrovascular and neurodegenerative pathologies and clinical hypothyroidism (as operationalized by 
clinician interview during a clinical examination). We analyzed National Alzheimer's Coordinating Center (NACC) data gathered from U.S. Alzheimer's Disease Centers (ADCs). We focused on treated hypothyroidism since this was by far the most common clinical TH syndrome in this sample. Because hypothyroidism previously has been associated with cardiovascular risk factors (Abreu et al., 2017; Delpont et al., 2016; Imaizumi et al., 2004; Pasqualetti et al., 2015), we hypothesized that hypothyroidism would be associated with cerebrovascular pathology. As a secondary objective, we conducted a separate analysis of the relationship between hypothyroidism and clinical cardiovascular disease and risk factors in a complementary sample of non-autopsied participants.

\section{Methods}

\section{Data sources and study populations}

Data were obtained from NACC's Uniform Data Set (UDS) on participants who had been prospectively evaluated at one of 34 past and present U.S. ADCs between September 2005 and December 2016. Participants were evaluated annually at an ADC using a standardized clinical protocol (Beekly DL, 2004, 2007). Participants enrolled with any level of cognition from normal to demented. Individual ADCs recruit and enroll participants according to their own protocols. UDS data were collected annually via trained clinicians or interviewers through in-person office visits at each ADC. At each visit, subjects received physical and neurological examinations, plus a battery of neuropsychological assessments.

Neuropathology data were collected from neuropathologists based on autopsy results for subjects who died and had consented to autopsy evaluation at an ADC. Individual ADCs received institutional review board approval and written informed consent was obtained from all participants and their study co-participants.

The current analyses focused on two samples: 1.) UDS participants who had been autopsied (autopsy sample) and 2.) UDS participants who were still alive or who had died but had not been autopsied (clinic sample). Participants were excluded from the autopsy sample if they had 1.) age of death younger than 55 years (due to small numbers); 2.) rare disease(s) such as Down's syndrome, prion disease, autosomal dominant genetic diseases (i.e. early onset AD), or FTLD; 3.) reported use of hyperthyroid medication at any visit; or, 4.) were missing information on thyroid disease, demographics, health history or common neuropathologies. Participants were excluded from the clinic sample if they had 1.) age at baseline younger than 55 years; 2.) reported use of hyperthyroid medication at any visit; or, 3.) were missing information on thyroid disease, demographics, or health history. Figure 1 shows the study sample flow and distribution of concurrent thyroid disease and medication use.

Among 2,847 autopsied participants who met inclusion criteria, 25\% had a history of thyroid disease and/or were taking hypothyroid medications, while in the clinic sample $22 \%$ of 26,930 eligible participants had a history of thyroid disease or hypothyroid medication use. Most participants with thyroid disease and hypothyroid treatment reported active thyroid disease ( $93 \%$ in the autopsy sample, $82 \%$ in the clinical sample). The majority of persons who reported thyroid disease without hypothyroid treatment had inactive thyroid disease (62\% of the autopsy sample and $46 \%$ of the clinical sample). Due to low numbers and potential differences in thyroid disease status, we excluded subjects who reported thyroid 
disease without hypothyroid treatment or reported no thyroid disease but had hypothyroid treatment. The primary analyses focused on participants with thyroid disease and hypothyroid medication use compared to those who did not report thyroid disease or medication use (Figure 1).

\section{Thyroid disease and treatment}

History of thyroid disease was assessed at each UDS visit based on clinician interview from 2005 to 2014, and was recorded as recent, remote, or not present. For follow-up participant visits after 2015, thyroid disease diagnosis (yes, no) was based on clinician assessment. In the current analysis, we categorized participants based on whether they had thyroid disease present at one or more visits. Reported use of hyperthyroid medications (methimazole, propylthiouracil, and sodium iodide I-131) or hypothyroid medications (e.g. levothyroxine, thyroid desiccated, liothyronine, and liotrix) was recorded at each UDS visit. Participants were categorized into 4 groups based on reported thyroid disease status and hypothyroid medication status across followup: thyroid disease with hypothyroid treatment $(\mathrm{TH}+\mathrm{T}+)$, no thyroid disease and no treatment ( $\mathrm{TH}-\mathrm{T}-$ ), thyroid disease without hypothyroid treatment $(\mathrm{TH}+\mathrm{T}-$ ), and thyroid disease not reported but hypothyroid medication reported $(\mathrm{TH}-\mathrm{T}+$ ).

\section{Covariates}

Demographic characteristics included age, sex, education, race/ethnicity, and ADC. History of comorbidities, such as depression, vascular risk factors, diabetes, cardiovascular disease, and stroke were evaluated during each clinical visit. $A P O E$ genotyping was performed on consenting participants. $A P O E \varepsilon 4$ allele status was classified as at least one or none. Assessment of cognitive status was made at each visit; dementia diagnosis was made by either a single clinician or consensus group of clinicians, after a review of all evaluation information available. Clinical impairment was quantified at each study visit with the Clinical Dementia Rating Scale Sum of Boxes (CDR-SB)(JC, 1993), a composite measure of the overall level of cognitive impairment and functional disability that is based on clinical judgment and study co-participant report.

\section{Neuropathological Features}

ADCs followed consensus-based guidelines but conducted neuropathologic assessments according to center-specific protocols. Neuropathologists used a standardized form and results were uploaded to the NACC database. Operationalization of AD neuropathologic changes (ADNC) included Consortium to Establish a Registry for Alzheimer's Disease (CERAD) stages of $A \beta$ neuritic plaque densities (none, sparse, moderate, frequent) (Mirra SS, 1991) and Braak stages for tau neurofibrillary pathology (0, I-III, IV, V, VI) (Braak et al., 2006). ADNC was defined regardless of an individual's documented cognitive status. ADNC as defined by new NIA-Alzheimer's Association criteria (Hyman et al., 2012) also includes Thal staging (Beekly et al., 2004; Thal DR, 2002) for A $\beta$ plaques, however this was not available for most participants before 2014. Presence of cortical microinfarcts (infarcts in the cortex only seen microscopically) and/or gross infarcts (small or large artery infarcts that are visible at the time of autopsy) were recorded regardless of age. Cerebral amyloid angiopathy, atherosclerosis, and arteriolosclerosis were classified as none, mild, moderate, or severe. Assessment for Lewy bodies followed recognized guidelines (McKeith IG, 2005). 
Lewy body disease (LBD) was defined as presence of Lewy bodies in any brain region examined. Subtypes of LBD were classified as none, brainstem predominant, limbic (transitional), neocortical (diffuse), or other or unknown region. Hippocampal sclerosis was categorized as present based on neuropathologic diagnosis (forms prior to 2014) or if recorded as unilateral, bilateral, or laterality unknown (forms after 2014).

\section{Statistical Analyses}

Characteristics of participants were described stratified by thyroid disease status. KruskalWallis and $\chi^{2}$ tests and tests evaluated whether characteristics differed in distribution between those with and without treated hypothyroidism (TH+T+vs TH-T-). Multivariable logistic regression models assessed associations between hypothyroidism and neuropathologic characteristics. Models included adjustment for demographics (age at death, sex, race, education) and clinical characteristics (CDR-SB at last visit and history of the following comorbidities: hypertension, hypercholesterolemia, diabetes, smoking, atrial fibrillation, heart attack, congestive heart failure). Generalized estimating equations were used to account for clustering of participant within ADCs and robust standard errors were calculated. Several sensitivity analyses were conducted. First, we examined the effect of including all participants with reported thyroid disease or hypothyroid medications. Next, we tested the effects of additional adjustment for APOE $\varepsilon 4$ allele and BMI.

We further explored the associations between thyroid disease with vascular disease in both the autopsy and clinical samples. In the autopsy sample, associations were assessed between vascular risk factors, cardiovascular disease, clinical cerebrovascular disease, and cerebrovascular pathologies. Because criteria for pathologies became more standardized in NACC forms after 2014, these analyses were stratified based on those who had died 20052013 and those who had died after 2014 (no overlap in the samples). In the clinical sample we explored associations between vascular risk factors, cardiovascular disease, clinical cerebrovascular disease and hypothyroidism in those with and without dementia at baseline.

All tests were two-sided with $a=0.05$. Analyses were conducted using R (version 3.2.1, R Core Team, 2015).

\section{RESULTS}

There were 555 autopsied participants with treated hypothyroidism and 2,146 without known thyroid disease. These participants were followed an average of 2.8 years (SD: 2.3 years) and a majority were demented by their last visit (78\%). There were 4,598 clinical participants with treated hypothyroidism and 20,045 without thyroid disease, who were followed an average of 2.8 years (SD: 3.0 years) and 32\% were demented at the time of enrollment.

Participants with thyroid disease were more likely to be older, female, Caucasian, and to have a history of vascular risk factors and disease (Table 1). Predicted probability of thyroid disease by age at death is shown in Figure 2A for males and females. Before controlling for other factors, participants with thyroid disease were less likely to be demented (Table 1), and were less likely to have high ADNC or LBD (Table 2); in terms of cerebrovascular 
pathologies, gross infarcts and atherosclerosis were more common in those with reported thyroid disease (Table 2).

\section{Pathologies and hypothyroidism}

In multivariable logistic regression models, severe atherosclerosis was associated with a $35 \%$ higher odds of hypothyroidism after adjustment for potential confounders (Table 3). By contrast, neither CERAD neuritic plaque score nor Braak NFT Stage for neurofibrillary tangles were associated with hypothyroidism in this model (Table 3). Findings did not change substantially with adjustment for $A P O E \varepsilon 4$ allele or BMI, but missing data was greater, so we present findings from primary models. There was a trend for lower prevalence of LBD in those with hypothyroidism; this trend was observed in both men and women (Figure 2B). Among 630 participants aged $>85$ years at death and without severe ADNC (e.g. Braak Stage 0-IV) there was a trend for HS pathology to be inversely associated with hypothyroidism (OR: 0.51; 95\% CI: 0.25, 1.03; p=0.06).

\section{Clinical vascular disease and hypothyroidism}

Hypercholesterolemia, atrial fibrillation, and cerebrovascular disease were associated with hypothyroidism in subsamples. Only atrial fibrillation was associated with hypothyroidism in those autopsied 2005-2014 although odds ratios were similar to results from those autopsied after 2014 (Table 4). Among participants who were evaluated since 2014 (with a newer form), hypercholesterolemia and gross infarcts were significantly associated with hypothyroidism but the associations with atherosclerosis were no longer significant. Additionally, in the clinical sample, hypercholesterolemia and diabetes were associated with hypothyroidism in those without dementia at baseline (Table 5). In those with dementia, cerebrovascular disease was also associated with hypothyroidism in those with dementia (Table 5; Figure 2C), with increased ORs for atrial fibrillation and congestive heart failure.

\section{Discussion}

In the large NACC data set, clinical hypothyroidism was associated with cardiovascular and cerebrovascular diseases. Hypothyroidism was substantially more common in females than males. Hypothyroidism was associated with severe atherosclerosis pathology and with gross infarcts in autopsied participants. In both the autopsy sample and the clinical (no autopsy) sample, hypothyroidism was associated with vascular disease, especially hypercholesterolemia. These results provide some new directions for studying two of the prevalent conditions linked to aging-dementia and hypothyroidism.

The strongest associations in this study were between hypothyroidism and cerebrovascular/ cardiovascular parameters and pathologies. There have been prior reports that have broadly similar findings: hypothyroidism has been associated with hypercholesterolemia, atrial fibrillation, diabetes, and, ultimately, cerebrovascular disease that is perhaps independent of other known cardiovascular risk factors (Abreu et al., 2017; Chaker et al., 2016a; Delitala et al., 2017; van Tienhoven-Wind and Dullaart, 2015). Importantly, TH replacement can lead to improved cardiovascular risk factors (Abreu et al., 2017; Adamarczuk-Janczyszyn et al., 2016). Our study of autopsied and non-autopsied participants enabled some important new 
findings to provide insights into the pathogenetic mechanisms involved. Specifically, autopsied persons with treated hypothyroidism tended to have higher risk for severe atherosclerosis in the Circle of Willis, and also gross infarcts on pathological examination of the brains in the more recent autopsy subset. Brain infarct data collection became more standardized after 2014, which may account for the association between gross infarcts and treated hypothyroidism in the more recent autopsies; including higher quality infarct data may also have attenuated the finding with atherosclerosis in the same model. However, there may also be differences in sample characteristics by time-period as history of atrial fibrillation was associated with hypothyroidism in those autopsied 2005-2013 while hypercholesterolemia was associated with autopsies from 2014. In a prior study of carotid plaques detected with ultrasound, plaque burden was associated with low, but not high, thyroid stimulating hormone values (Dorr et al., 2008), while a separate study found that "subclinical" hypothyroidism was associated with higher carotid intima-media thickness (Peixoto de Miranda et al., 2016). It is challenging to adequately control for all the various possible confounders related to cardiovascular risk and hypothyroidism. For example, the factors that contribute to risk for incident stroke may not be the same as those that alter the brain's compensatory changes afterward (see (Chaker et al., 2016a; Delpont et al., 2016)). Future prospective studies will be required to tease out the specific biologic mechanisms. However, these data provide strong indication of an association between treated hypothyroidism and large-vessel cerebrovascular disease. Our findings that hypercholesterolemia, atrial fibrillation, and stroke/TIA were also associated with hypothyroidism in the clinical sample (non-autopsied sample) also lend further support to this hypothesis.

The correlations between hypothyroidism and neurodegenerative diseases were weaker than those related to cerebrovascular disease. We evaluated three main types of pathology-defined neurodegenerative diseases in this study: ADNC, LBD, and HS (a key pathology in Cerebral Age-Related TDP-43 With Sclerosis [CARTS]). Our study found no evidence of an association between hypothyroidism and AD-type amyloid plaques or neurofibrillary tangles. When other parameters were controlled for in regression-based models, there was no trend for "protective" or "harmful" effects of hypothyroidism. By contrast, there did seem to be a trend for LBD pathology to be inversely associated with treated hypothyroidism.

Although there seems to be a potential of confounding due to sexual dimorphism (men have higher risk for DLB (Nelson et al., 2010), and, as underscored by the current study, women have higher risk for hypothyroidism), this association did not seem to be biasing the results: both men and women that were treated for hypothyroidism showed a trend for lower risk for LBD pathology. Age is also an important potential confounder since, on average, the persons with hypothyroidism in this dataset were somewhat older than those without diagnosed thyroid disease. However, to the best of our knowledge, this is the first evidence of a link between TH disease and LBD, and merits further study.

We also assessed the potential association between HS pathology and hypothyroidism. We had previously found genetic evidence of risk, and also CSF findings, linking TH dysregulation and HS-Aging/CARTS pathology (Nelson et al., 2016a; Nelson et al., 2016b). In the current study, we found no evidence of a robust association between hypothyroidism and HS pathology. We note that there was a trend for lower prevalence of HS among those 
with treated hypothyroidism $(\mathrm{p}=0.06)$ in a subsample (the oldest-old without high Braak NFT Stages); however, there was a trend for slightly increased prevalence of HS pathology among those with treated hypothyroidism overall $(\mathrm{p}=0.2)$. This merits further study given the many sources of potential confounding (e.g., many false-negative HS cases on pathology) in this study, and the lack of substantial numbers of hyperthyroid cases in this sample.

There are limitations and caveats relevant to these analyses. We had no measure of "subclinical" thyroid hormone disease (Grossman et al., 2016; Surks et al., 2004; Visser et al., 2013); and levothyroxine use can lead to "over-replacement" (iatrogenic hyperthyroidism), which can be symptomatic with anxiety and atrial fibrillation. Thus a person treated for hypothyroidism (usually with levothyroxine) may be considered to represent an example of hypothyroidism, and/or has brain changes secondary to the hormone replacing drug, and/or is impacted by an underlying (possibly autoimmune) condition that manifests with hypothyroidism and with other systemic and/or neurologic effects. There is some evidence that persons treated with levothyroxine often maintain above-average thyroid stimulating levels (Razvi et al., 2016), and thus are presumably still 'hypothyroid' in a clinico-biologic sense, but, it is unclear how this may have affected our findings. In the autopsy sample, participants with thyroid disease tended to be older, less likely to be demented, and were far more likely to be female. These observations are interesting in their own right. While we adjusted for these factors in regression models, it is important to keep these potential confounders in mind. "Dementia research clinics", as represented by most U.S. ADCs, follow samples that differ from a broader population, drawing from a sample comprising mostly Caucasian, relatively high socioeconomic status persons with relatively high risk for clinical $\mathrm{AD}$ - not a population-based sample.

Despite those concerns, the NACC database represents one of the world's largest and highest-quality multicenter databases, with both detailed clinical (including medication use and cognitive status) and pathological information. The database has been extensively audited. Our findings may thus have more generalizable significance. In addition, we conducted additional secondary and sensitivity analyses to inform generalizability of our results; findings were similar between autopsied and non-autopsied participants as well as those autopsied with more recent standardized data collection forms vs. earlier forms.

In summary, our analyses highlight an association between hypothyroidism and risk for cerebrovascular disease, but not AD pathology. Hypothyroidism was associated with severe atherosclerosis pathology and with gross infarcts in a subset of participants. In both the autopsy sample and the clinical sample, hypothyroidism was associated with hypercholesterolemia and cerebrovascular disease. In the clinical sample, hypothyroidism was associated with stroke and transient ischemic attacks among those with dementia at baseline. Approximately one-quarter of all the research subjects reported some type of THlinked disease. These results indicate that further study on the link between causes of dementia and thyroid disease is merited to provide guidance for clinicians to optimize management of TH levels in the elderly. 


\section{Acknowledgments}

We are deeply grateful to all of the study participants, clinicians, and other workers at ADCs that make this research possible. We also thank NACC staff for help with NACC data. NIH funding included R01 AG057187.

The NACC database is funded by NIA/NIH Grant U01 AG016976. NACC data are contributed by the NIA-funded ADCs: P30 AG019610 (PI Eric Reiman, MD), P30 AG013846 (PI Neil Kowall, MD), P50 AG008702 (PI Scott Small, MD), P50 AG025688 (PI Allan Levey, MD, PhD), P50 AG047266 (PI Todd Golde, MD, PhD), P30 AG010133 (PI Andrew Saykin, PsyD), P50 AG005146 (PI Marilyn Albert, PhD), P50 AG005134 (PI Bradley Hyman, MD, PhD), P50 AG016574 (PI Ronald Petersen, MD, PhD), P50 AG005138 (PI Mary Sano, PhD), P30 AG008051 (PI Thomas Wisniewski, MD), P30 AG013854 (PI M. Marsel Mesulam, MD), P30 AG008017 (PI Jeffrey Kaye, MD), P30 AG010161 (PI David Bennett, MD), P50 AG047366 (PI Victor Henderson, MD, MS), P30 AG010129 (PI Charles DeCarli, MD), P50 AG016573 (PI Frank LaFerla, PhD), P50 AG005131 (PI James Brewer, MD, PhD), P50 AG023501 (PI Bruce Miller, MD), P30 AG035982 (PI Russell Swerdlow, MD), P30 AG028383 (PI Linda Van Eldik, PhD), P30 AG053760 (PI Henry Paulson, MD, PhD), P30 AG010124 (PI John Trojanowski, MD, PhD), P50 AG005133 (PI Oscar Lopez, MD), P50 AG005142 (PI Helena Chui, MD), P30 AG012300 (PI Roger Rosenberg, MD), P30 AG049638 (PI Suzanne Craft, PhD), P50 AG005136 (PI Thomas Grabowski, MD), P50 AG033514 (PI Sanjay Asthana, MD, FRCP), P50 AG005681 (PI John Morris, MD), P50 AG047270 (PI Stephen Strittmatter, MD, PhD). This study was also supported by R01 NS061933 and P30 AG028383.

No author's institution has contracts relating to this research through which it or any other organization may stand to gain financially now or in the future.

No other agreements of authors or their institutions that could be seen as involving a financial interest in this work.

We verify that the data contained in the manuscript being submitted have not been previously published, and will not be submitted elsewhere while under consideration at Neurobiology of Aging.

We verify that appropriate IRB approval and procedures were used concerning human subjects.

We verify that all authors have reviewed the contents of the manuscript being submitted, approve of its contents and validate the accuracy of the data.

\section{References cited}

Abreu IM, Lau E, de Sousa Pinto B, Carvalho D. Subclinical hypothyroidism: to treat or not to treat, that is the question! A systematic review with meta-analysis on lipid profile. Endocrine connections. 2017; 6(3):188-199. [PubMed: 28249936]

Adamarczuk-Janczyszyn M, Zdrojowy-Welna A, Rogala N, Zatonska K, Bednarek-Tupikowska G. Evaluation of Selected Atherosclerosis Risk Factors in Women with Subclinical Hypothyroidism Treated with L-Thyroxine. Adv Clin Exp Med. 2016; 25(3):457-463. [PubMed: 27629733]

Akintola AA, Jansen SW, van Bodegom D, van der Grond J, Westendorp RG, de Craen AJ, van Heemst D. Subclinical hypothyroidism and cognitive function in people over 60 years: a systematic review and meta-analysis. Front Aging Neurosci. 2015; 7:150. [PubMed: 26321946]

Beekly DL, Ramos EM, Van Belle G, Deitrich W, Clark AD, Jacka ME, Kukull WA. The National Alzheimer's Coordinating Center (NACC) Database: an Alzheimer disease database. Alzheimer Disease \& Associated Disorders. 2004; 18(4):270-277. [PubMed: 15592144]

Beekly DL, R E, Lee WW, Deitrich WD, Jacka ME, Wu J, Hubbard JL, Koepsell TD, Morris JC, Kukull WA. The National Alzheimer's Coordinating Center (NACC) database: the Uniform Data Set. Alzheimer Dis Assoc Disord. 2007; 21(3):249-258. [PubMed: 17804958]

Beekly DL, R E, Van BG, Deitrich W, Clark AD, Jacka ME, Kukull WA. The National Alzheimer's Coordinating Center (NACC) Database: an Alzheimer disease database. Alzheimer Dis Assoc Disord. 2004; 18(4):270-277. [PubMed: 15592144]

Boelaert K, Franklyn JA. Thyroid hormone in health and disease. J Endocrinol. 2005; 187(1):1-15. [PubMed: 16214936]

Braak H, Alafuzoff I, Arzberger T, Kretzschmar H, Del Tredici K. Staging of Alzheimer diseaseassociated neurofibrillary pathology using paraffin sections and immunocytochemistry. Acta Neuropathol. 2006; 112(4):389-404. [PubMed: 16906426] 
Canaris GJ, Manowitz NR, Mayor G, Ridgway EC. The Colorado thyroid disease prevalence study. Arch Intern Med. 2000; 160(4):526-534. [PubMed: 10695693]

Chaker L, Baumgartner C, den Elzen WP, Collet TH, Ikram MA, Blum MR, Dehghan A, Drechsler C, Luben RN, Portegies ML, Iervasi G, Medici M, Stott DJ, Dullaart RP, Ford I, Bremner A, Newman AB, Wanner C, Sgarbi JA, Dorr M, Longstreth WT Jr, Psaty BM, Ferrucci L, Maciel RM, Westendorp RG, Jukema JW, Ceresini G, Imaizumi M, Hofman A, Bakker SJ, Franklyn JA, Khaw KT, Bauer DC, Walsh JP, Razvi S, Gussekloo J, Volzke H, Franco OH, Cappola AR, Rodondi N, Peeters RP, Thyroid Studies C. Thyroid Function Within the Reference Range and the Risk of Stroke: An Individual Participant Data Analysis. J Clin Endocrinol Metab. 2016a; 101(11): 4270-4282. [PubMed: 27603906]

Chaker L, Korevaar TIM, Rizopoulos D, Collet TH, Volzke H, Hofman A, Rodondi N, Cappola AR, Peeters RP, Franco OH. Defining optimal health range for thyroid function based on the risk of cardiovascular disease. J Clin Endocrinol Metab. 2017

Chaker L, van den Berg ME, Niemeijer MN, Franco OH, Dehghan A, Hofman A, Rijnbeek PR, Deckers JW, Eijgelsheim M, Stricker BH, Peeters RP. Thyroid Function and Sudden Cardiac Death: A Prospective Population-Based Cohort Study. Circulation. 2016b; 134(10):713-722. [PubMed: 27601558]

Chaker L, Wolters FJ, Bos D, Korevaar TI, Hofman A, van der Lugt A, Koudstaal PJ, Franco OH, Dehghan A, Vernooij MW, Peeters RP, Ikram MA. Thyroid function and the risk of dementia: The Rotterdam Study. Neurology. 2016c; 87(16):1688-1695. [PubMed: 27638924]

Collet TH, Gussekloo J, Bauer DC, den Elzen WP, Cappola AR, Balmer P, Iervasi G, Asvold BO, Sgarbi JA, Volzke H, Gencer B, Maciel RM, Molinaro S, Bremner A, Luben RN, Maisonneuve P, Cornuz J, Newman AB, Khaw KT, Westendorp RG, Franklyn JA, Vittinghoff E, Walsh JP, Rodondi N, Thyroid Studies C. Subclinical hyperthyroidism and the risk of coronary heart disease and mortality. Arch Intern Med. 2012; 172(10):799-809. [PubMed: 22529182]

Cooke GE, M S, Correia N, O’Mara SM, Gibney J. Hippocampal volume is decreased in adults with hypothyroidism. Thyroid Official Journal of the American Thyroid Association. 2014; 24(3):433440. [PubMed: 24205791]

de Jong FJ, Masaki K, Chen H, Remaley AT, Breteler MM, Petrovitch H, White LR, Launer LJ. Thyroid function, the risk of dementia and neuropathologic changes: the Honolulu-Asia aging study. Neurobiology of aging. 2009; 30(4):600-606. [PubMed: 17870208]

Delitala AP, Fanciulli G, Pes GM, Maioli M, Delitala G. Thyroid Hormones, Metabolic Syndrome and Its Components. Endocr Metab Immune Disord Drug Targets. 2017

Delpont B, Aboa-Eboule C, Durier J, Petit JM, Daumas A, Legris N, Daubail B, Giroud M, Bejot Y. Associations between Thyroid Stimulating Hormone Levels and Both Severity and Early Outcome of Patients with Ischemic Stroke. Eur Neurol. 2016; 76(3-4):125-131. [PubMed: 27577238]

Dorr M, Empen K, Robinson DM, Wallaschofski H, Felix SB, Volzke H. The association of thyroid function with carotid artery plaque burden and strokes in a population-based sample from a previously iodine-deficient area. Eur J Endocrinol. 2008; 159(2):145-152. [PubMed: 18495692]

Empson M, Flood V, Ma G, Eastman CJ, Mitchell P. Prevalence of thyroid disease in an older Australian population. Intern Med J. 2007; 37(7):448-455. [PubMed: 17547723]

Frohlich E, Wahl R. Thyroid Autoimmunity: Role of Anti-thyroid Antibodies in Thyroid and ExtraThyroidal Diseases. Front Immunol. 2017; 8:521. [PubMed: 28536577]

Gencer B, Collet TH, Virgini V, Auer R, Rodondi N. Subclinical thyroid dysfunction and cardiovascular outcomes among prospective cohort studies. Endocr Metab Immune Disord Drug Targets. 2013; 13(1):4-12. [PubMed: 23369133]

Grossman A, Weiss A, Koren-Morag N, Shimon I, Beloosesky Y, Meyerovitch J. Subclinical Thyroid Disease and Mortality in the Elderly: A Retrospective Cohort Study. Am J Med. 2016; 129(4): 423-430. [PubMed: 26714213]

Hyman BT, Phelps CH, Beach TG, Bigio EH, Cairns NJ, Carrillo MC, Dickson DW, Duyckaerts C, Frosch MP, Masliah E, Mirra SS, Nelson PT, Schneider JA, Thal DR, Thies B, Trojanowski JQ, Vinters HV, Montine TJ. National Institute on Aging-Alzheimer's Association guidelines for the neuropathologic assessment of Alzheimer's disease. Alzheimers Dement. 2012; 8(1):1-13. [PubMed: 22265587] 
Imaizumi M, Akahoshi M, Ichimaru S, Nakashima E, Hida A, Soda M, Usa T, Ashizawa K, Yokoyama N, Maeda R, Nagataki S, Eguchi K. Risk for ischemic heart disease and all-cause mortality in subclinical hypothyroidism. J Clin Endocrinol Metab. 2004; 89(7):3365-3370. [PubMed: 15240616]

JC M. The Clinical Dementia Rating (CDR): current version and scoring rules. Neurology. 1993; 43:2412-2414.

Koromilas C, L C, Schulpis KH, Kalafatakis K, Zarros A, Tsakiris S. Structural and functional alterations in the hippocampus due to hypothyroidism. Metab Brain Dis. 2010; 25(3):339-354. [PubMed: 20886273]

Maenhaut, C., Christophe, D., Vassart, G., Dumont, J., Roger, PP., Opitz, R. Ontogeny, Anatomy, Metabolism and Physiology of the Thyroid. In: De Groot, LJ.Chrousos, G.Dungan, K.Feingold, KR.Grossman, A.Hershman, JM.Koch, C.Korbonits, M.McLachlan, R.New, M.Purnell, J.Rebar, R.Singer, F., Vinik, A., editors. Endotext. South Dartmouth (MA): 2000.

Mafrica F, Fodale V. Thyroid function, Alzheimer's disease and postoperative cognitive dysfunction: a tale of dangerous liaisons? J Alzheimers Dis. 2008; 14(1):95-105. [PubMed: 18525131]

McKeith IG, D D, Lowe J, Emre M, O’brien JT, Feldman H, Cummings J, Duda JE, Lippa C, Perry EK, Aarsland D. Diagnosis and management of dementia with Lewy bodies: third report of the DLB Consortium. Neurology. 2005; 65(12):1863-1872. [PubMed: 16237129]

Mirra SS, H A, McKeel D, Sumi SM, Crain BJ, Brownlee LM, et al. The Consortium to Establish a Registry for Alzheimer's Disease (CERAD). Part II Standardization of the neuropathologic assessment of Alzheimer's disease. Neurology. 1991; 41(4):479-486. [PubMed: 2011243]

Moon JH. Endocrine Risk Factors for Cognitive Impairment. Endocrinol Metab (Seoul). 2016; 31(2): 185-192. [PubMed: 27118278]

Moon JH, Park YJ, Kim TH, Han JW, Choi SH, Lim S, Park DJ, Kim KW, Jang HC. Lower-butnormal serum TSH level is associated with the development or progression of cognitive impairment in elderly: Korean Longitudinal Study on Health and Aging (KLoSHA). J Clin Endocrinol Metab. 2014; 99(2):424-432. [PubMed: 24285689]

Nelson PT, Katsumata Y, Nho K, Artiushin SC, Jicha GA, Wang WX, Abner EL, Saykin AJ, Kukull WA, Alzheimer's Disease Neuroimaging, I. Fardo DW. Genomics and CSF analyses implicate thyroid hormone in hippocampal sclerosis of aging. Acta Neuropathol. 2016a

Nelson PT, Schmitt FA, Jicha GA, Kryscio RJ, Abner EL, Smith CD, Van Eldik LJ, Markesbery WR. Association between male gender and cortical Lewy body pathology in large autopsy series. J Neurol. 2010

Nelson PT, Trojanowski JQ, Abner EL, Al-Janabi OM, Jicha GA, Schmitt FA, Smith CD, Fardo DW, Wang WX, Kryscio RJ, Neltner JH, Kukull WA, Cykowski MD, Van Eldik LJ, Ighodaro ET. "New Old Pathologies": AD, PART, and Cerebral Age-Related TDP-43 With Sclerosis (CARTS). Journal of neuropathology and experimental neurology. 2016b; 75(6):482-498. [PubMed: 27209644]

Pasqualetti G, Pagano G, Rengo G, Ferrara N, Monzani F. Subclinical Hypothyroidism and Cognitive Impairment: Systematic Review and Meta-Analysis. J Clin Endocrinol Metab. 2015; 100(11): 4240-4248. [PubMed: 26305618]

Peixoto de Miranda EJ, Bittencourt MS, Pereira AC, Goulart AC, Santos IS, Lotufo PA, Bensenor IM. Subclinical hypothyroidism is associated with higher carotid intima-media thickness in crosssectional analysis of the Brazilian Longitudinal Study of Adult Health (ELSA-Brasil). Nutr Metab Cardiovasc Dis. 2016; 26(10):915-921. [PubMed: 27389191]

Razvi S, Ingoe L, Ryan V, Pearce SH, Wilkes S. Study of Optimal Replacement of Thyroxine in the Elderly (SORTED) - results from the feasibility randomised controlled trial. Thyroid Res. 2016; 9:5. [PubMed: 27766119]

Rieben C, Segna D, da Costa BR, Collet TH, Chaker L, Aubert CE, Baumgartner C, Almeida OP, Hogervorst E, Trompet S, Masaki K, Mooijaart SP, Gussekloo J, Peeters RP, Bauer DC, Aujesky D, Rodondi N. Subclinical Thyroid Dysfunction and the Risk of Cognitive Decline: a MetaAnalysis of Prospective Cohort Studies. J Clin Endocrinol Metab. 2016; 101(12):4945-4954. [PubMed: 27689250]

Rosman NP. The neuropathology of congenital hypothyroidism. Adv Exp Med Biol. 1972; 30:337366. [PubMed: 4662273] 
Sampaolo S, Campos-Barros A, Mazziotti G, Carlomagno S, Sannino V, Amato G, Carella C, Di Iorio G. Increased cerebrospinal fluid levels of $3,3^{\prime}, 5^{\prime}$-triiodothyronine in patients with Alzheimer's disease. J Clin Endocrinol Metab. 2005; 90(1):198-202. [PubMed: 15483087]

Sawin CT, Castelli WP, Hershman JM, McNamara P, Bacharach P. The aging thyroid. Thyroid deficiency in the Framingham Study. Arch Intern Med. 1985; 145(8):1386-1388. [PubMed: 4026469]

Squizzato A, Gerdes VE, Brandjes DP, Buller HR, Stam J. Thyroid diseases and cerebrovascular disease. Stroke; a journal of cerebral circulation. 2005; 36(10):2302-2310.

Surks MI, Ortiz E, Daniels GH, Sawin CT, Col NF, Cobin RH, Franklyn JA, Hershman JM, Burman KD, Denke MA, Gorman C, Cooper RS, Weissman NJ. Subclinical thyroid disease: scientific review and guidelines for diagnosis and management. JAMA. 2004; 291(2):228-238. [PubMed: 14722150]

Tan ZS, Beiser A, Vasan RS, Au R, Auerbach S, Kiel DP, Wolf PA, Seshadri S. Thyroid function and the risk of Alzheimer disease: the Framingham Study. Arch Intern Med. 2008; 168(14):15141520. [PubMed: 18663163]

Tan ZS, Vasan RS. Thyroid function and Alzheimer's disease. J Alzheimers Dis. 2009; 16(3):503-507. [PubMed: 19276542]

Thal DR, R U, Orantes M, Braak H. Phases of A beta-deposition in the human brain and its relevance for the development of AD. Neurology. 2002; 58:1791-1800. [PubMed: 12084879]

van Osch LA, Hogervorst E, Combrinck M, Smith AD. Low thyroid-stimulating hormone as an independent risk factor for Alzheimer disease. Neurology. 2004; 62(11):1967-1971. [PubMed: 15184598]

van Tienhoven-Wind LJ, Dullaart RP. Low-normal thyroid function and the pathogenesis of common cardio-metabolic disorders. European journal of clinical investigation. 2015; 45(5):494-503. [PubMed: 25690560]

Vanderpump MP. The epidemiology of thyroid disease. Br Med Bull. 2011; 99:39-51. [PubMed: 21893493]

Verburg FA, Grelle I, Tatschner K, Reiners C, Luster M. Prevalence of thyroid disorders in elderly people in Germany. A screening study in a country with endemic goitre. Nuklearmedizin. 2017; 56(1):9-13. [PubMed: 28124062]

Visser WE, Visser TJ, Peeters RP. Thyroid disorders in older adults. Endocrinol Metab Clin North Am. 2013; 42(2):287-303. [PubMed: 23702402]

Wu Y, Pei Y, Wang F, Xu D, Cui W. Higher FT4 or TSH below the normal range are associated with increased risk of dementia: a meta-analysis of 11 studies. Sci Rep. 2016; 6:31975. [PubMed: 27558885]

Yeap BB, Alfonso H, Chubb SA, Puri G, Hankey GJ, Flicker L, Almeida OP. Higher free thyroxine levels predict increased incidence of dementia in older men: the Health in Men Study. J Clin Endocrinol Metab. 2012; 97(12):E2230-2237. [PubMed: 22977271]

Yeap BB, Alfonso H, Hankey GJ, Flicker L, Golledge J, Norman PE, Chubb SA. Higher free thyroxine levels are associated with all-cause mortality in euthyroid older men: the Health In Men Study. Eur J Endocrinol. 2013; 169(4):401-408. [PubMed: 23853210]

Zhang X, Xie Y, Ding C, Xiao J, Tang Y, Jiang X, Shan H, Lin Y, Zhu Y, Li C, Hu D, Ling Z, Xu G, Sheng L. Subclinical hypothyroidism and risk of cerebral small vessel disease: a hospital-based observational study. Clin Endocrinol (Oxf). 2017 


\section{Highlights}

- $\quad$ Thyroid hormone disease is common among the elderly but pathologic correlates are not known.

- In a large sample (National Alzheimer's Coordinating Center, comprising almost 30,000 total research subjects), approximately $1 / 4$ of individuals reported treated hypothyroidism.

- Among both autopsied and non-autopsied individuals, treated hypothyroidism was associated with cerebrovascular disease and stroke.

- $\quad$ Treated hypothyroidism was not associated with altered Alzheimer's disease pathology in this Sample. 


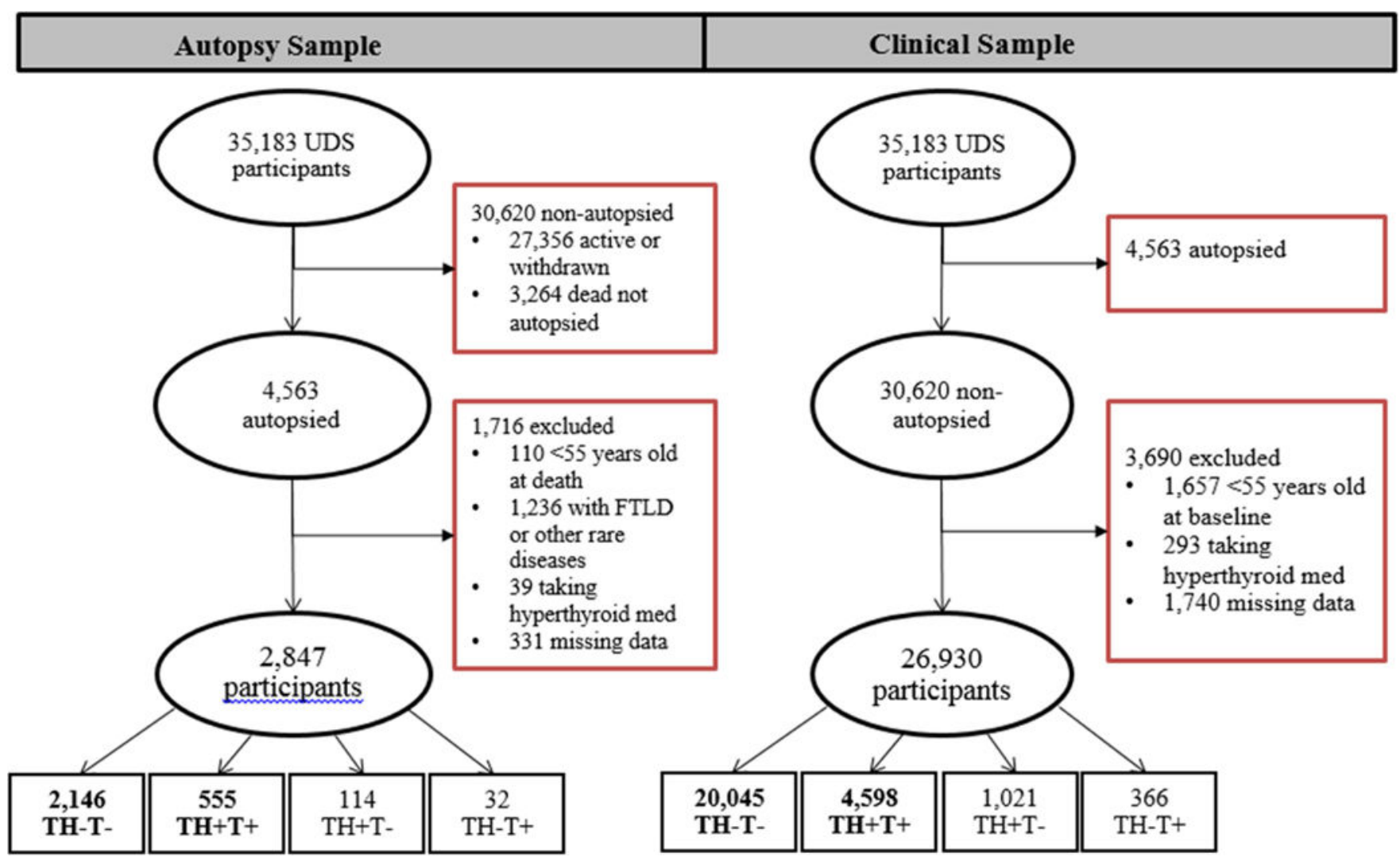

Figure 1. Study sample flow chart

FTLD, frontotemporal lobar degeneration; TH; Thyroid disease, T, Hypothyroid treatment;

NACC, National Alzheimer's Coordinating Center; UDS: Uniform Data Set. Primary

Analyses focus on comparisons between $\mathrm{TH}-\mathrm{T}-$ and $\mathrm{TH}-\mathrm{T}+$ participants. 
a

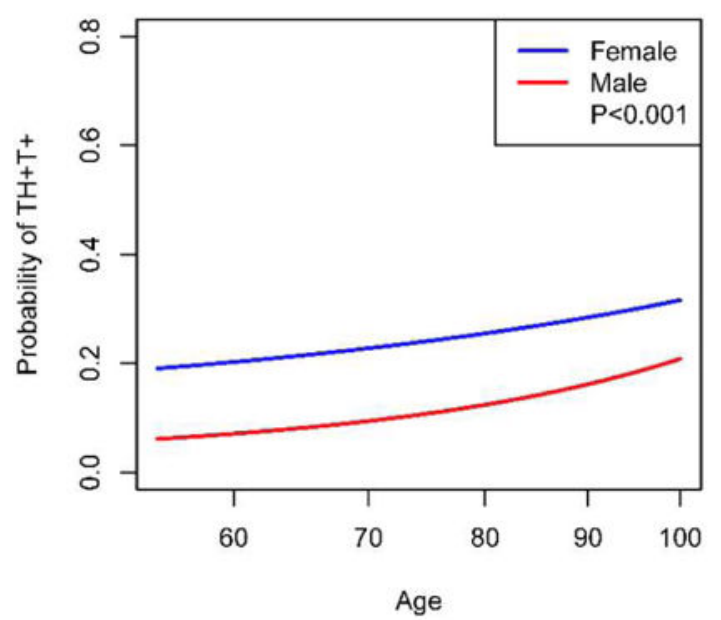

b

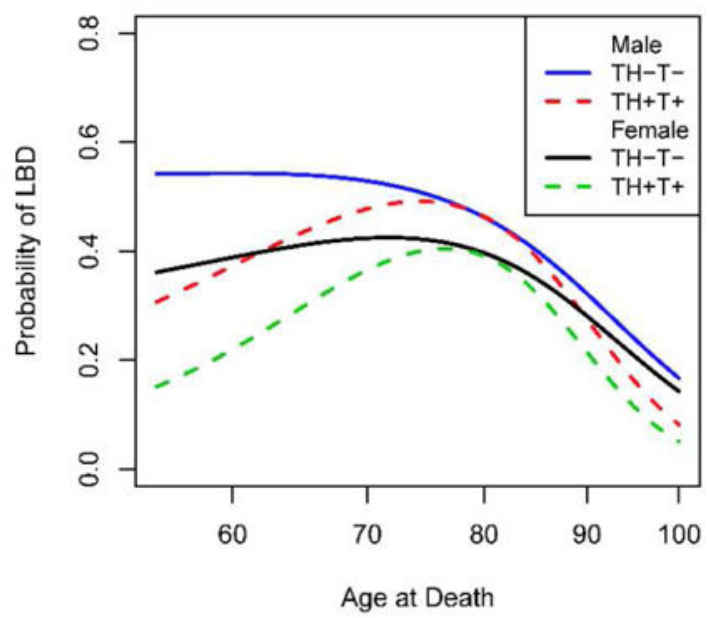

c

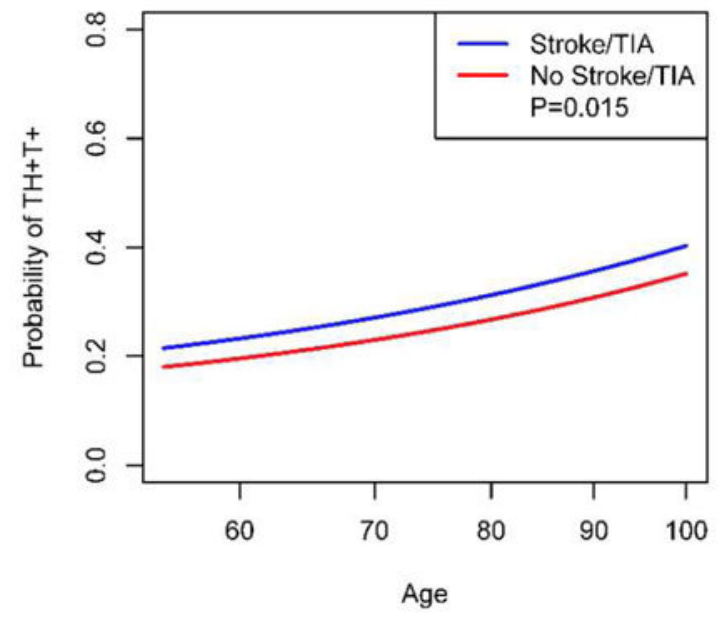

Figure 2. Study of associations between treated hypothyroidism (TH+T+) and various parameters across the aging spectrum

a. Probability of TH+T+ status by age and sex. Predicted probabilities shown based on logistic regression of $\mathrm{TH}+\mathrm{T}+$ with sex and age as predictors in the clinical sample. Across all ages, females are far more likely than males to be $\mathrm{TH}+\mathrm{T}+$ in this sample $(\mathrm{P}<0.001)$. b. Probability of Lewy body disease (LBD) and by age, stratified by $\mathrm{TH}+\mathrm{T}+$ status and sex. Predicted probabilities shown based on a logistic regression of LBD with age, sex, and thyroid disease status as predictors in the autopsy sample. The trend for an association between LBD and TH+T+ was borderline significant $(\mathrm{P}=0.06)$ but the pattern was strikingly similar for both sexes. c. Probability of $\mathrm{TH}+\mathrm{T}+$ by history of stroke or transient ischemic attack (TIA) in the clinical sample with dementia. Predicted probabilities shown based on logistic regression of $\mathrm{TH}+\mathrm{T}+$ with age at baseline, sex, non-white race, education, Clinical Dementia Rating sum of boxes score at baseline, depression, follow-up duration, and history of vascular risk factors or cardiovascular disease as predictors. There was a consistent trend 
across the aging spectrum for more stroke/TIA in persons with $\mathrm{TH}+\mathrm{T}+$ status, including after cardiovascular risk factors were included in the model $(\mathrm{P}=0.015)$. 
Brenowitz et al.

Page 17

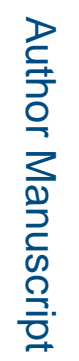

齐

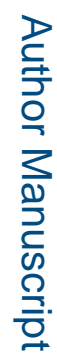

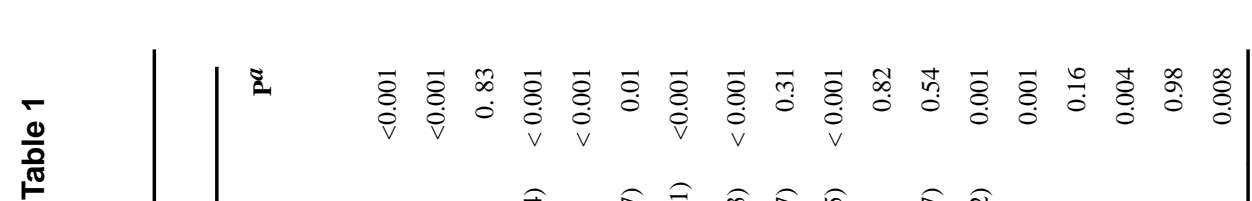

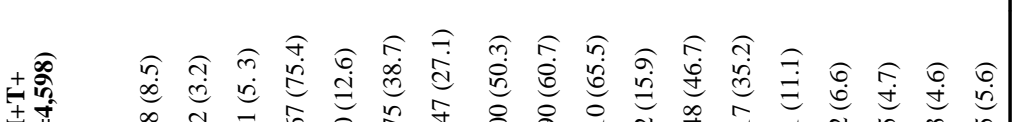

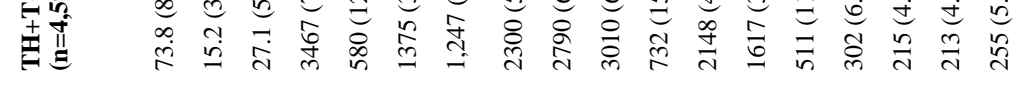

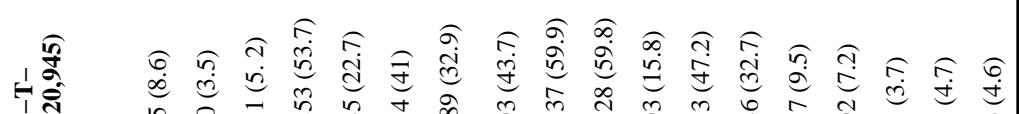

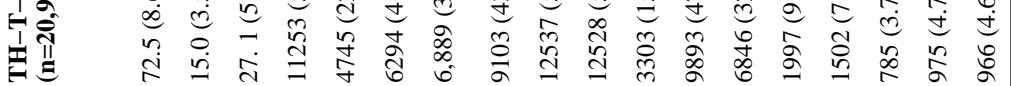

या

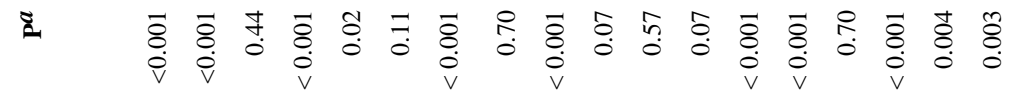

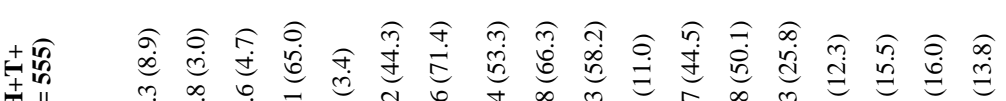
青先

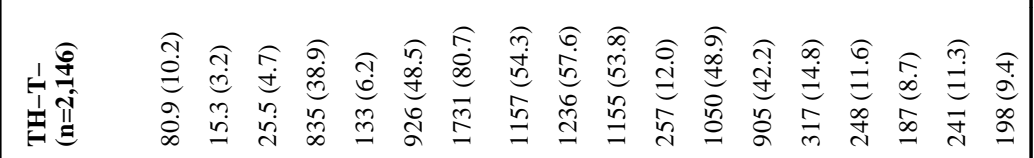

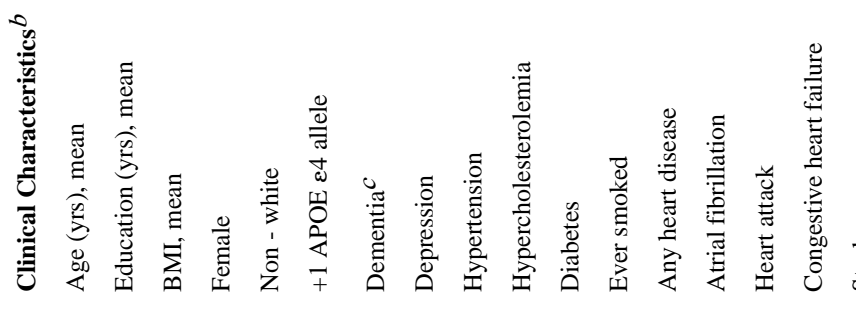

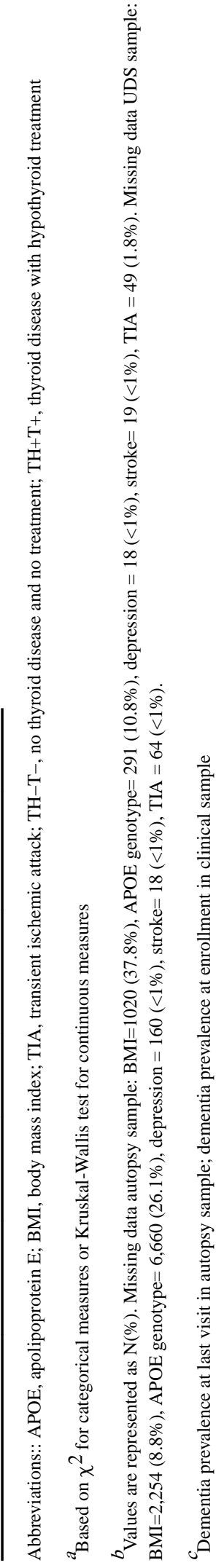
Neurobiol Aging. Author manuscript; available in PMC 2019 February 01. 
Table 2

Pathologic characteristics of participants with and without treated thyroid disease

\begin{tabular}{llll}
\hline \multicolumn{4}{c}{ Autopsy Sample } \\
\hline Pathologic Characteristics $^{\boldsymbol{a}}$ & TH-T- (n=2,186) & $\mathbf{T H + T + ( n = 5 7 0 )}$ & $\mathbf{P}^{\boldsymbol{b}}$ \\
Frequent Neuritic Plaques & $1168(54.4)$ & $261(47)$ & 0.002 \\
Braak NFT Stage V-VI & $1307(60.9)$ & $290(52.3)$ & $<0.001$ \\
Lewy body disease & $846(39.4)$ & $161(29)$ & $<0.001$ \\
Gross infarcts & $474(22.1)$ & $153(27.6)$ & 0.008 \\
Cortical microinfarcts & $348(16.2)$ & $95(17.1)$ & 0.655 \\
Severe CAA & $259(12.3)$ & $55(10.1)$ & 0.176 \\
Severe Atherosclerosis & $251(11.7)$ & $97(17.5)$ & $<0.001$ \\
Severe Arteriolosclerosis & $240(12.8)$ & $69(14)$ & 0.526 \\
Hippocampal Sclerosis & $183(8.5)$ & $57(10.3)$ & 0.229 \\
\hline
\end{tabular}

Abbreviations: CAA, cerebral amyloid angiopathy; NFT, neurofibrillary tangle; TH-T-, no thyroid disease and no treatment; $\mathrm{TH}+\mathrm{T}+$, thyroid disease with hypothyroid treatment

${ }^{a}$ Values are represented as N(\%). Missing data: $\mathrm{CAA}=42(1.6 \%)$, arteriolosclerosis $=336(12.4 \%)$.

$b_{\text {Based on }} \chi^{2}$ 
Table 3

Associations between neuropathologic features and treated $(\mathrm{TH}+\mathrm{T}+)$ thyroid disease $(\mathrm{n}=2,701)^{a}$

\begin{tabular}{lllll}
\hline & \multicolumn{3}{l}{ Thyroid Disease } & \\
\hline & OR & $\mathbf{9 5 \%}$ CI & P \\
Neuritic Plaque Density & & & & \\
$\quad$ None & 1.00 & - & - & \\
$\quad$ Sparse & 0.97 & 0.67 & 1.39 & 0.85 \\
$\quad$ Moderate & 0.98 & 0.68 & 1.41 & 0.91 \\
$\quad$ Frequent & 1.02 & 0.69 & 1.51 & 0.91 \\
Braak NFT Stage & & & & \\
$\quad$ Braak 0-III & 1.00 & - & - & \\
$\quad$ Braak IV & 0.86 & 0.63 & 1.19 & 0.36 \\
$\quad$ Braak V & 0.85 & 0.60 & 1.20 & 0.34 \\
Braak VI & 0.86 & 0.61 & 1.22 & 0.40 \\
Lewy body disease & 0.82 & 0.66 & 1.03 & 0.08 \\
Gross infarcts & 0.99 & 0.78 & 1.26 & 0.97 \\
Microinfarcts & 0.90 & 0.68 & 1.20 & 0.48 \\
Severe Atherosclerosis & $\mathbf{1 . 3 5}$ & $\mathbf{1 . 0 2}$ & $\mathbf{1 . 7 9}$ & $\mathbf{0 . 0 3}$ \\
Hippocampal Sclerosis & 1.14 & 0.81 & 1.60 & 0.45 \\
\hline
\end{tabular}

Abbreviations: CI, Confidence Interval; NFT, neurofibrillary tangle; OR, Odds Ratio

${ }^{a}$ Based on multivariable logistic regression model adjusted for age at death, sex, nonwhite race, education, Clinical Dementia Rating sum of boxes score at last visit, hypertension, hypercholesterolemia, smoking, diabetes, atrial fibrillation, heart attack, congestive heart failure, and interval between last visit and death 
로을

(

ग
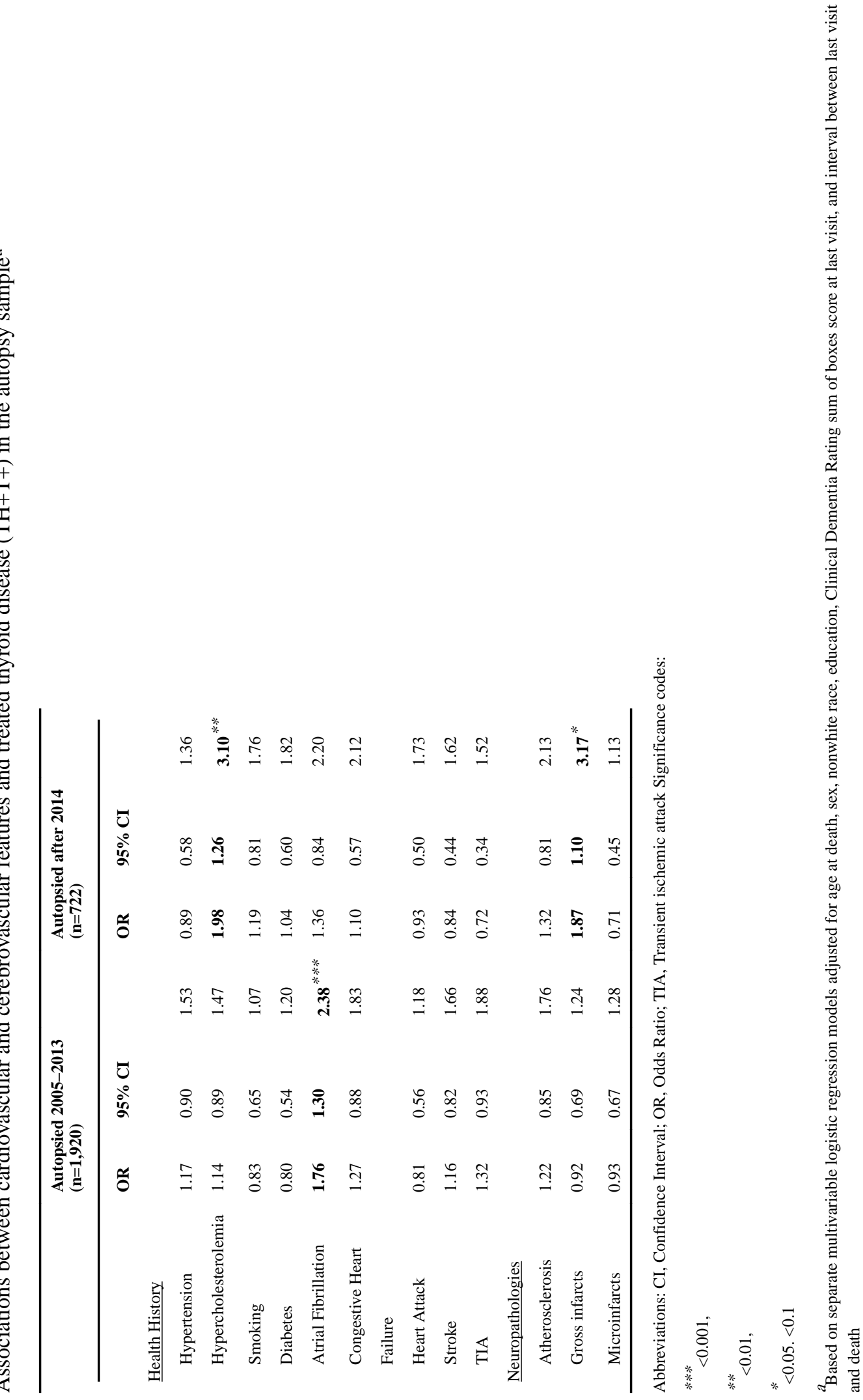

Neurobiol Aging. Author manuscript; available in PMC 2019 February 01. 


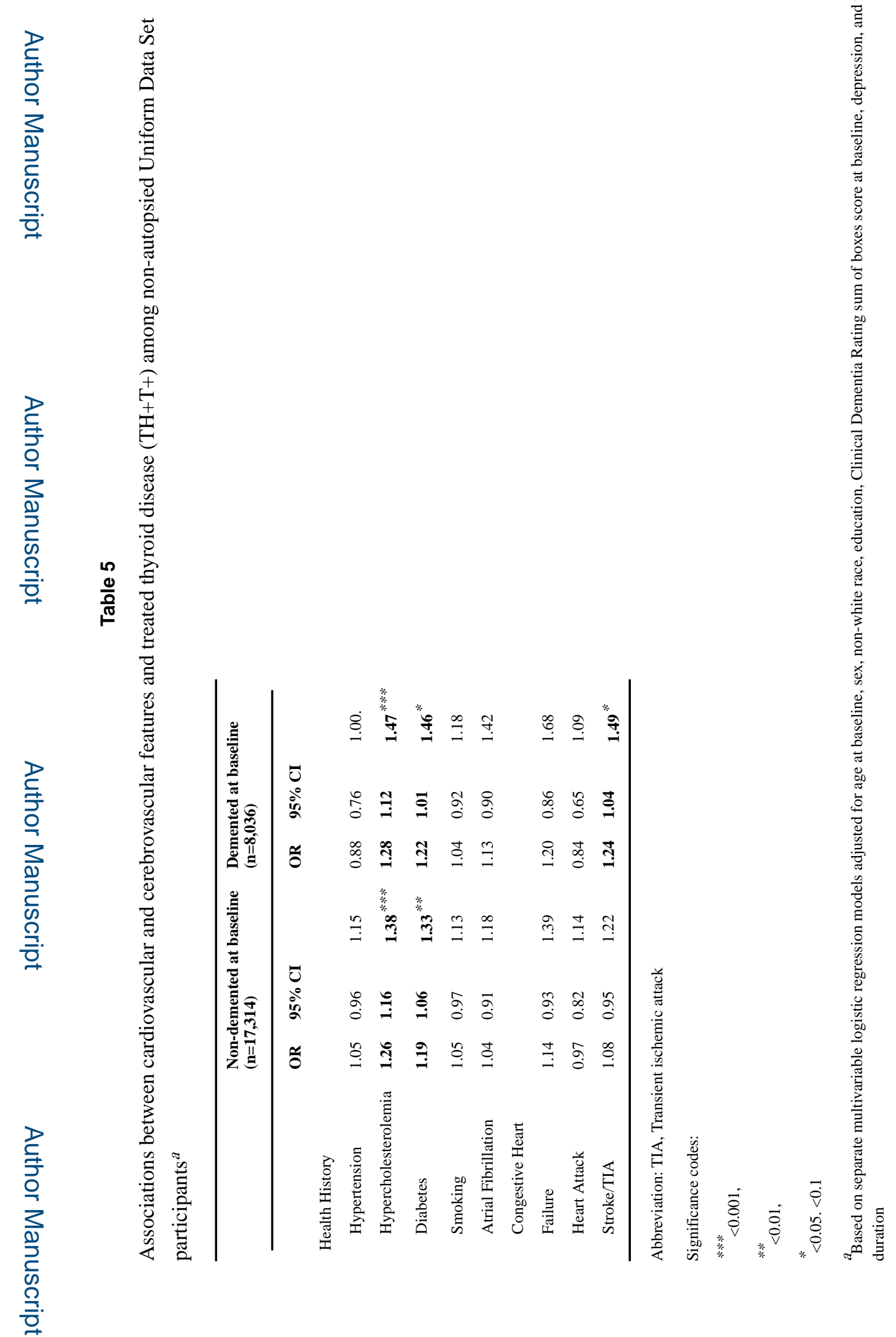

Neurobiol Aging. Author manuscript; available in PMC 2019 February 01. 